Article

\title{
Dynamic Monitoring and Analysis of Ecological Quality of Pingtan Comprehensive Experimental Zone, a New Type of Sea Island City, Based on RSEI
}

\author{
Xiaole Wen, Yanli Ming, Yonggang Gao * and Xinyu Hu \\ College of Environment and Resources, Fuzhou University, Fuzhou 350108, China; wenxl@fzu.edu.cn (X.W.); \\ mingyanli@foxmail.com (Y.M.); 386311895@163.com (X.H.) \\ * Correspondence: yggao@fzu.edu.cn; Tel.: +86-136-6506-9980
}

Received: 18 November 2019; Accepted: 14 December 2019; Published: 18 December 2019

\begin{abstract}
Islands face increasingly prominent environmental problems with rapid urbanization. Hence, timely and objective monitoring and evaluation of island ecology is of great significance. This study took the Pingtan Comprehensive Experimental Zone (PZ) in the east sea of Fujian Province of China as the research object. Based on remote sensing technology, four Landsat images from 2007 to 2017 and the remote sensing ecological index (RSEI) were used to explore the ecological status and space-time change. The results showed that from 2007 to 2011, the average RSEI decreased from 0.519 to 0.506 , indicating that the ecological quality generally showed a slight downward trend, mainly due to large-scale development brought by the construction; by 2014, although the ecology of the original area improved, the overall ecology was still declining with 0.502 mean RSEI mainly because of large-scale reclamation projects; by 2017 , the average RSEI rebounded to 0.523 , which was attributed to the fact that ecological construction and protection were emphasized in the construction of PZ, especially in reclamation areas. In conclusion, the increase of large area bare soil will lead to the decline of regional ecology, but the implementation of scientific ecological planning is conducive to ecological restoration and construction.
\end{abstract}

Keywords: RSEI; remote sensing; ecological status; dynamic motoring; Pingtan Island

\section{Introduction}

Islands, an important part of the marine system, have the special geographical position and resource superiority. Recently, with the rapid growth of population size and economy, the rapid development of islands has triggered a series of ecological and environmental problems, such as environmental degradation, coastline erosion, biodiversity degradation, etc [1-3]. As an important ecological function reservoir, the island is the carrier of human habitation and the fulcrum for the protection and utilization of the ocean. Unlike land, the island ecosystem has its own unique vulnerability, which is difficult to recover once disturbed or destroyed [4]. Therefore, timely and accurate monitoring of island ecology is of great significance for regional sustainable development.

Currently, there are many methods for ecological environment monitoring and evaluation. One of them, remote sensing spatial information technology, has been widely used in the field of ecological environment due to its advantages of rapid, real-time and large-scale monitoring [5-8], making up for the deficiency of traditional semi-quantitative ecological monitoring and evaluation methods, and providing an effective research method for regional ecological evaluation. Many scholars have made use of various remote sensing indices to study the ecological evaluation of different habitats, such as cities, rivers and forests, but most of them are limited to the monitoring and evaluation of a single piece of remote sensing information, such as using the vegetation index to evaluate forestry 
ecology [9], using the building index and surface temperature to evaluate the urban heat island [10] or using the water body index to extract river information and then evaluate the water environment [11]. However, in the actual ecosystem, the impact of a single ecological factor on the ecosystem is far less than the comprehensive effect of multiple factors, and the quality of the ecological environment is controlled by multiple ecological factors [12]. Hence, it is very important to explore the changing rules of ecological factors and their synergistic relationship and a comprehensive indicator that can couple these multiple factors is needed to carry out comprehensive evaluations of ecological environments from the perspective of ecological systems. Mozuderer et al. [13] used the normalised difference water index (NDWI), the modified normalised difference water index (MNDWI), the normalised difference pond index (NDPI), the normalised difference vegetation index (NDVI) and field data to classify Ramsar wetland Deepor Beel and then evaluate the ecosystem. Hazaymeh et al. [14] selected six commonly used indicators in agricultural drought, and integrated the three least relevant indicators selected by principal component analysis (PCA) to generate conditions for four agricultural drought categories. The data validation results showed that the method has certain applicability to monitoring of the agriculture drought conditions in semi-arid areas with moderately high spatial and time resolution images. Yanchuang et al. [15] found that the remotely sensed reflectivity is related to multifunctionality by studying the relationship between six albedo metrics and two VIs (normalized difference vegetation index (NDVI) and enhanced vegetation index (EVI)), and multifunctionality has been related to the alternative states in global drylands, indicating that albedo may monitor changes in dryland ecosystem functioning. In addition, there are also many studies on island ecosystems, most of which were based on ecological vulnerability research. Rodgers et al. [16] applied the integrated landscape indexes to assess the ecological health of Hawaiian Islands' coral reefs and associated waters. Farhan et al. [17] selected seven indicators to evaluate the ecological vulnerability of the Sabribu Islands in Indonesia. Mukherjee et al. [18] used the normalized difference water index (NDWI), the normalized difference vegetation index (NDVI), the visible and shortwave drought index (VSDI), the normalized multiband drought index (NMDI), the moisture stress index (MSI), land surface temperature (LST), etc., to explore the impact of climate change on the natural and socio-economic vulnerability of Mousuni Island.

There are still some shortcomings in the above results: Some of them affect promotion and use due to the cumbersome evaluation factors and the difficulty in obtaining the required evaluation indicators, while some reduce the credibility of evaluation result mainly because of the subjective manual setting. The remote sensing-based ecological index (RSEI) proposed by Xu [19] is an ecological evaluation index based on remote sensing information, which integrates multiple indicators dominated by natural factors and reflects the most intuitive ecological environment. It can make up for some of the shortcomings of the existing research methods, achieve objective and quantitative evaluation of regional ecological environment conditions, analyze and visualize the spatial and temporal evolution of an ecological environment and has verified its reliability in multiple regions [20-24].

As the fifth largest island in China and the largest island in Fujian, Pingtan Island is the nearest place to Taiwan in mainland China. In view of its special geographical location, Fujian Province officially approved the establishment of PZ in 2010 in accordance with the instructions of the state council on accelerating the construction of the economic zone on the west coast of the straits, and thus started a large-scale development boom of sea-island cities. As an island, the ecological environment of Pingtan Island was originally very fragile. Under large-scale construction, whether its ecological environment will further degrade has become a hot spot of public concern. Therefore, it is necessary to conduct measurements of the ecological changes triggered by the construction of the PZ, and to provide a scientific decision-making basis for the next stage of development and construction.

Currently, there are few studies on the construction of sea-island cities and the ecological environment changes induced by them, while there are few reports on the evaluation of the ecological status of the construction of $\mathrm{PZ}$, which is extremely unfavorable for the scientific guidance of the ecological protection in the construction of PZ. In view of this, this paper uses the remote sensing-based ecological index (RSEI) evaluation method to conduct a rapid and objective evaluation of the ecological 
status of the PZ in the early-middle stage (2007-2017), analyzes the characteristics and causes of the spatio-temporal changes of the ecological status of Pingtan Island during the period of rapid development over the last 10 years and provides a scientific decision-making basis for protecting the ecological environment in the further construction of PZ.

\section{Materials and Methods}

\subsection{Study Area}

PZ is located in Pingtan County in the eastern waters of Fujian Province. Pingtan County consists of 126 islands and nearly a thousand reefs, including the main island Haitan Island (also known as Pingtan Island, $25^{\circ} 16^{\prime}-25^{\circ} 44^{\prime} \mathrm{N} 119^{\circ} 32^{\prime}-120^{\circ} 10^{\prime}$ E), which is the largest island in Fujian and the fifth largest island in China with an area of $267 \mathrm{~km}^{2}$, and this study uses this island as a study area (Figure 1). The terrain of the island is higher in the north and south, mostly with the rolling hills and low mountains, and is lower in the middle with the marine plain. The area has short summers and long winters, is warm and humid and has an average annual temperature of $19.6^{\circ} \mathrm{C}$ and an annual precipitation of $1161.4 \mathrm{~mm}$.

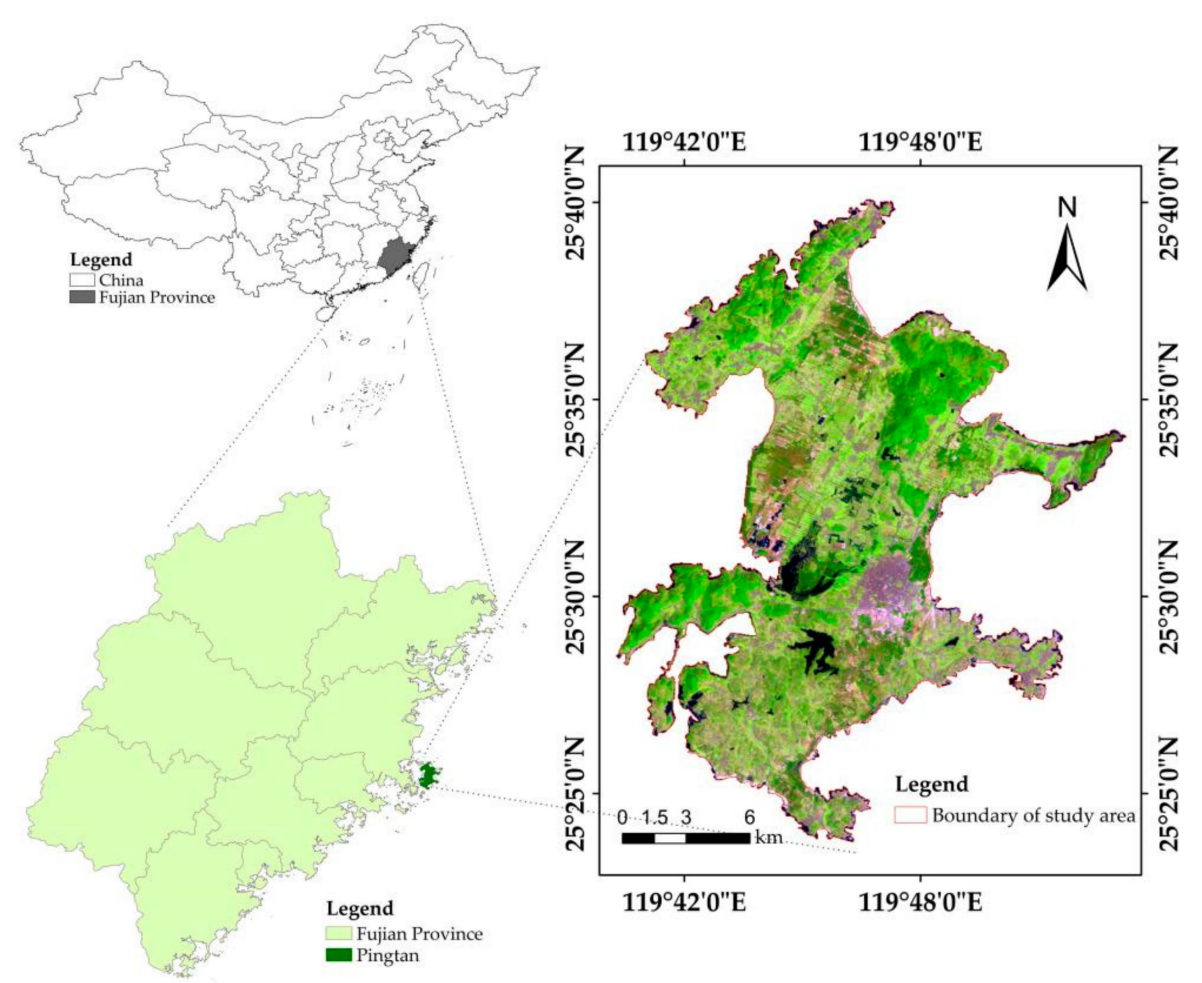

Figure 1. Location of the study area.

\subsection{Data Resources and Image Pre-Processing}

This study selected Landsat TM and OLI/TIRS images on 2007-09-14, 2011-09-09, 2014-09-01 and 2017-09-25, and the four images are close to each other in time, with a maximum difference of about one month (Table 1). Therefore, the vegetation has a similar growth status, which ensures the comparability of the ecological research results.

The TM images were co-registered to the OLI/TIRS using second-order polynomial and nearest-neighbour re-sampling, and the root mean square error (RMSE) of registration was less than 0.5 pixels. Then radiometric correction was carried out to convert the digital number (DN) values into planetary TOA reflectance. For TM images, the IACM atmospheric correction model of Chander et al. [25] and Chavez [26] was used. For OLI images, the algorithms provided in the Landsat 8 Data 
Users Handbook posted by the USGS website were used to reduce the differences in terrain, light and atmosphere of the images with different phases [27].

Table 1. Landsat images used for analysis.

\begin{tabular}{cc}
\hline Satellite & Acquisition Date \\
\hline \multirow{2}{*}{ Landsat TM } & $2007-09-14$ \\
& $2011-09-09$ \\
Landsat OLI/TIRS & $2014-09-01$ \\
& $2017-09-25$ \\
\hline
\end{tabular}

\subsection{Methodology}

The remote sensing-based ecological index (RSEI) selects four factors related to human survival, such as greenness, wetness, heal and dryness, as ecological evaluation factors among many natural factors reflecting ecological quality, and quickly extracts representative images from remote sensing images through remote sensing information enhancement technology. The information of the indicators, namely, the normalized difference vegetation index (NDVI) [28], wetness component of the tasseled cap transformation (TCT) [29], the normalized difference impervious surface index (NDBSI) [30] and the land surface temperature (LST) [31] represent greenness, wetness, dryness and heat, respectively.

\subsubsection{The Greenness Index}

The normalized difference vegetation index (NDVI), one of the most widely used vegetation indexes, is a vegetation index that has demonstrated its usefulness in many ecological studies [32,33]. Thus, NDVI can be selected as the greenness index in this paper, and its formula is:

$$
\mathrm{NDVI}=(\mathrm{NIR}-\mathrm{Red}) /(\mathrm{NIR}+\mathrm{Red})
$$

where NIR and Red are the amounts of near-infrared and red light, respectively.

\subsubsection{The Wetness Index}

Tasseled cap wetness (TCW) has demonstrated its sensitivity to the moisture conditions of vegetation, water and soil [34]. Thus, the TCW is used as the wetness index here, and it can be estimated for Landsat TM and Landsat 8 using Equations (2) [29] and (3) [35], respectively.

$$
\begin{gathered}
\mathrm{TCW}_{\mathrm{TM}}=0.0315 \rho_{\text {Blue }}+0.2012 \rho_{\text {Green }}+0.3102 \rho_{\text {Red }}+0.1594 \rho_{\mathrm{NIR}}-0.6806 \rho_{\mathrm{SWIR} 1}-0.6109 \rho_{\text {SWIR2 }} \\
\mathrm{TCW}_{8}=0.1511 \rho_{\text {Blue }}+0.1973 \rho_{\text {Green }}+0.3283 \rho_{\text {Red }}+0.3407 \rho_{\text {NIR }}-0.7117 \rho_{\text {SWIR } 1}-0.4559 \rho_{\text {SWIR2 }}
\end{gathered}
$$

where the $\rho_{\mathrm{i}}$ is the reflectance of each band in the TM and OLI sensors, respectively.

\subsubsection{The Dryness Index}

Soil drying, mainly because of construction land and bare soil, will cause serious harm to a regional ecological environment. Thus, this paper chose the normalized difference impervious surface index (NDBSI), combined with the index-based built-up index (IBI) and soil index (SI), and they are calculated as follows [36,37]:

$$
\begin{aligned}
& \mathrm{NDBSI}=(\mathrm{IBI}+\mathrm{SI}) / 2 \\
& \text { IBI }=\left\{2 \rho_{\text {SWIR } 1 /}\left(\rho_{\text {SWIR } 1}+\rho_{\text {NIR }}\right)-\left[\rho_{\text {NIR }}\left(\rho_{\text {NIR }}+\rho_{\text {Red }}\right)+\rho_{\text {Green }}\left(\rho_{\text {Green }}+\rho_{\text {SWIR } 1}\right)\right]\right\} /\left\{2 \rho_{\text {SWIR } 1 /}\right. \\
& \left.\left(\rho_{\mathrm{SWIR} 1}+\rho_{\mathrm{NIR}}\right)+\left[\rho_{\mathrm{NIR} /}\left(\rho_{\mathrm{NIR}}+\rho_{\mathrm{Red}}\right)+\rho_{\mathrm{Green} /}\left(\rho_{\mathrm{Green}}+\rho_{\mathrm{SWIR} 1}\right)\right]\right\} \\
& \mathrm{SI}=\left[\left(\rho_{\text {SWIR } 1}+\rho_{\text {Red }}\right)-\left(\rho_{\text {NIR }}+\rho_{\text {Blue }}\right)\right] /\left[\left(\rho_{\text {SWIR } 1}+\rho_{\text {Red }}\right)+\left(\rho_{\text {NIR }}+\rho_{\text {Blue }}\right)\right]
\end{aligned}
$$

where the $\rho \mathrm{i}$ is the reflectance of each band in the TM and OLI sensors, respectively. 


\subsubsection{The Heat Index}

The heat index is represented by the land surface temperature (LST). While there are two thermal infrared bands in the Landsat 8 TIRS sensor, this paper only chose band 10 to retrieve the LST because of the radiation calibration problem of band 11 [38]. For TM, of course, we still got the LST based on band 6 [39]. First, the digital number (DN) values was converted into the spectral radiance at the sensors aperture $\left(\mathrm{L}_{\lambda}\right)$, expressed as:

$$
\mathrm{L}_{\lambda}=\mathrm{G}_{\text {rescale }} \times \mathrm{Q}_{\text {cal }}+\mathrm{B}_{\text {rescale }}
$$

where $G_{\text {scale }}$ is the band-specific rescaling gain factor, $Q_{\text {cal }}$ is quantized calibrated pixel value $(D N)$, and $B_{\text {rescale }}$ is the band-specific rescaling bias factor. The at-sensor spectral radiance $\left(L_{\lambda}\right)$ can be converted into effective at-sensor brightness temperature using the following formula:

$$
\mathrm{T}_{\lambda}=\mathrm{K} 2 / \ln \left(\mathrm{K} 1 / \mathrm{L}_{\lambda}+1\right)
$$

where $T_{\lambda}$ is the effective at-sensor brightness temperature, and $\mathrm{K} 1\left(607.76 \mathrm{~W} /\left(\mathrm{m}^{2} \cdot \mathrm{sr} \cdot \mu \mathrm{m}\right)\right.$ for TM band 6 and $774.89 \mathrm{~W} /\left(\mathrm{m}^{2} \cdot \mathrm{sr} \cdot \mu \mathrm{m}\right)$ for TIR band 10) and K2 (260.56K for TM band 6 and $1321.08 \mathrm{~K}$ for landsat 8 band 10) are the calibration constant 1 and 2, respectively. Finally, $T_{\lambda}$ was used to obtain the LST, and the formula is expressed as:

$$
\operatorname{LST}=\mathrm{T}_{\lambda /}[1+(\lambda \mathrm{T} / \rho) \ln \varepsilon]
$$

where $\lambda$ is the wavelength of the emitted radiance $(11.435 \mu \mathrm{m}$ for TM band 6 and $10.9 \mu \mathrm{m}$ for TIR band $10) ; \rho$ is a contant $\left(1.438 \times 10^{-2} \mathrm{mK}\right) ; \varepsilon$ is the surface emissivity, which can be estimated by NDVI using Sobrino's model [40].

\subsubsection{Construction of Remote Sensing-Based Ecological Index (RSEI)}

The four component indicators obtained above are coupled by principal component analysis (PCA), and the first principal component (PC1) was used to build the RSEI, the biggest advantage of which is that the weight of the integrated indexes is not determined artificially, but is determined automatically and objectively according to the contribution of each indicator to PC1. Thus, the possible deviation of the result caused by the weight setting that varies from person to person and from method to method is avoided in the calculation, which greatly improves the objectivity and credibility of the result. Due to the uneven dimensions of the above four factors, if these factors are directly used to calculate PCA, the weight of each index will be unbalanced. Therefore, the above factors are supposed to be normalized to convert each index value into a dimensionless value within the range of $0-1$ before PCA is calculated. The general normalization formula of each index is:

$$
\mathrm{NI}_{\mathrm{i}}=\left(\mathrm{I}_{\mathrm{i}}-\mathrm{I}_{\min }\right) /\left(\mathrm{I}_{\max }-\mathrm{I}_{\min }\right)
$$

where NIi is a normalized index value; Ii is the value of the index in pixel I; Imax is the maximum value of this index; Imin is the minimum value of this index.

After the normalization of the four indicators, PC1 was calculated with the help of the principal component analysis module in ENVI software. In order to make the large value represent the good ecology, 1 can be used to minus PC1 to get the initial ecological index RESIO

$$
\mathrm{RSEI}_{0}=1-\mathrm{PC} 1
$$

Moreover, in order to the obtain comparable RSEI values in different time and space, RSEI values should be normalized as well:

$$
\mathrm{RSEI}=\left(\mathrm{RSEI}_{0}-\mathrm{RSEI}_{0 \_\min }\right) /\left(\mathrm{RSEI}_{0 \_ \text {max }}-\mathrm{RSE}_{\mathrm{I} \_\_ \text {min }}\right)
$$




\subsubsection{Calculation of RSEI}

First, four ecological indexes of four year images were obtained, and then they were normalized and combined into a new image. In addition, in order not to let the water affect the results of principal component analysis, the modified normalized water index (MNDWI) was used to mask the water. Finally, principal component transformation was performed on the newly synthesized image to obtain RSEI images of different years (Figure 2).

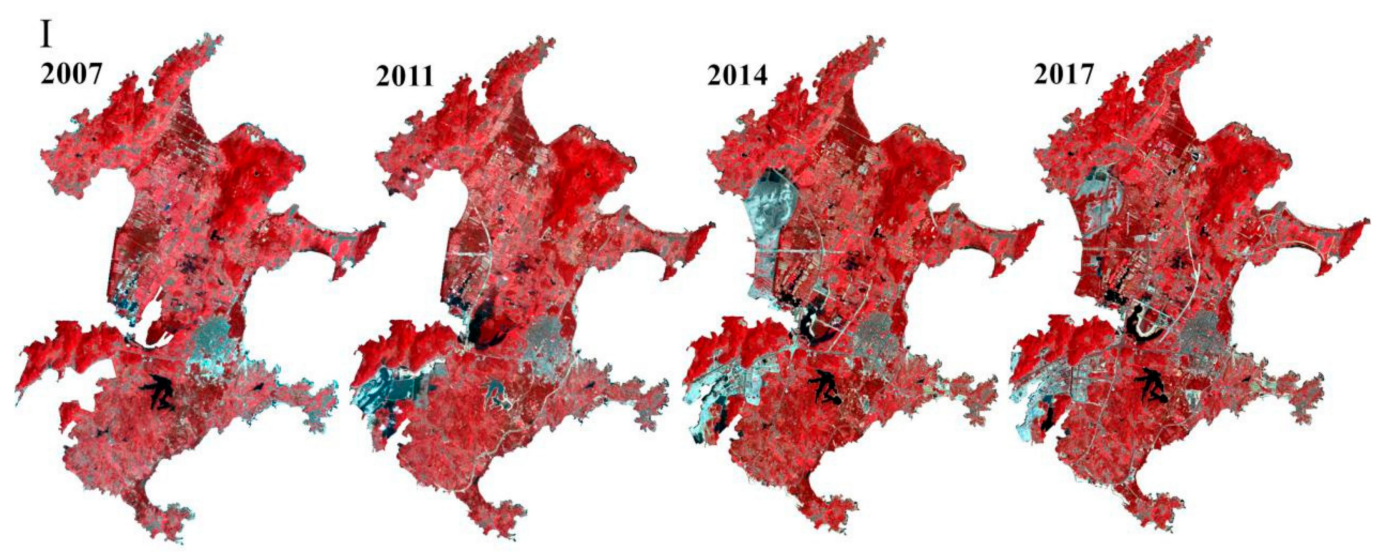

(a) Original images (RGB: 432)

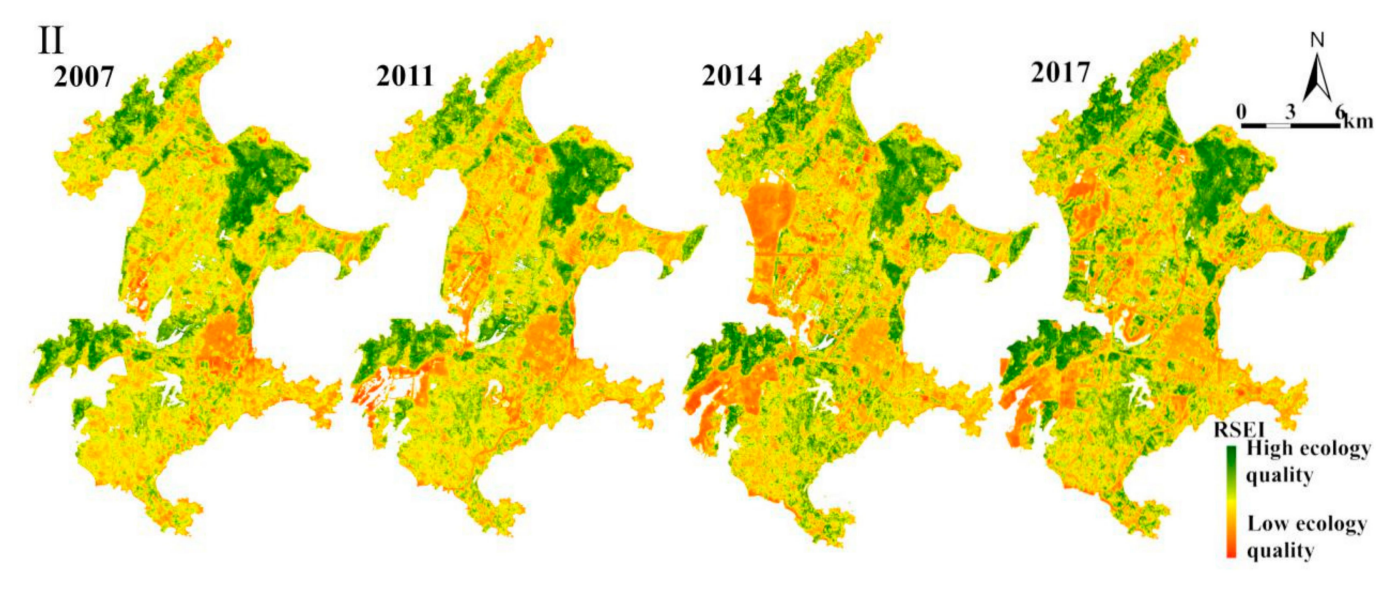

(b) Corresponding remote sensing-based ecological index (RSEI) images

Figure 2. Original and corresponding remote sensing-based ecological index (RSEI) images of Pingtan Island.

\section{Results}

\subsection{Pingtan Island Ecological Status}

The PCA was used to obtain the load values of PC1 for the four indicators in the study area in 2007, 2011, 2014 and 2017. Then, the mean values of the four indicators and RSEI in each year and the magnitude of their changes were calculated, as shown in Table 2. 
Table 2. Statistics of four indicators and RSEI in different years.

\begin{tabular}{|c|c|c|c|c|c|c|c|c|c|c|c|}
\hline \multirow{2}{*}{ Index } & \multicolumn{2}{|c|}{2007} & \multirow{2}{*}{$\begin{array}{c}\text { Rate } \\
07-11 \\
(\%)\end{array}$} & \multicolumn{2}{|c|}{2011} & \multirow{2}{*}{$\begin{array}{c}\text { Rate } \\
11-14 \\
(\%)\end{array}$} & \multicolumn{2}{|c|}{2014} & \multirow{2}{*}{$\begin{array}{c}\text { Rate } \\
14-17 \\
(\%)\end{array}$} & \multicolumn{2}{|c|}{2017} \\
\hline & Mean & $\begin{array}{c}\text { PC1 } \\
\text { Load }\end{array}$ & & Mean & $\begin{array}{c}\text { PC1 } \\
\text { Load }\end{array}$ & & Mean & $\begin{array}{c}\text { PC1 } \\
\text { Load }\end{array}$ & & Mean & $\begin{array}{c}\text { PC1 } \\
\text { Load }\end{array}$ \\
\hline NDVI & 0.628 & -0.474 & -8.92 & 0.572 & -0.485 & 6.64 & 0.610 & -0.496 & 1.97 & 0.622 & -0.497 \\
\hline WET & 0.757 & -0.509 & -5.02 & 0.719 & -0.509 & 0.83 & 0.725 & -0.504 & -6.76 & 0.676 & -0.506 \\
\hline NDBSI & 0.536 & 0.541 & 1.66 & 0.550 & 0.541 & -4.18 & 0.527 & 0.535 & 4.93 & 0.553 & 0.537 \\
\hline LST & 0.448 & 0.473 & 23.44 & 0.553 & 0.461 & -17.72 & 0.455 & 0.462 & -4.62 & 0.434 & 0.457 \\
\hline RSEI & 0.519 & & -2.50 & 0.506 & & -0.79 & 0.502 & & 4.18 & 0.523 & \\
\hline
\end{tabular}

Table 2 demonstrates that, during the study period, the ecological quality of the PZ first decreased and then increased. The average RSEI decreased from 0.519 in 2007 to 0.506 in 2011, with a decrease of $2.50 \%$; and then continued to decrease to 0.502 in 2014 , with a decrease of $0.79 \%$, and finally rose to 0.523 in 2017, with an increase of $4.18 \%$.

At the initial stage of the construction of the PZ, that is, from 2007 to 2011, the average value of greenness and humidity, which had a positive effect on the ecological status, decreased by $8.92 \%$ and $5.02 \%$, respectively. Moreover, the dryness and heat, which had a negative effect on the ecological status, increased by $1.66 \%$ and $23.44 \%$, respectively. Thus, the overall ecological situation had a downward trend. In the middle period of construction of Pingtan Island, that is, from 2011 to 2014, the average green value favorable to the ecological situation increased by $6.64 \%$, the humidity increased by $0.83 \%$, the dryness unfavorable to the ecological situation decreased by $4.18 \%$ and the heat decreased by $17.72 \%$, but, as the reclamation area has more bare land, the overall ecology declined. From 2014 to 2017 , the ecologically beneficial greenness increased by $1.97 \%$, the humidity decreased by $6.76 \%$, the ecologically unfavorable dryness increased by $4.93 \%$ and the heat decreased by $4.62 \%$. On the whole, the negative effects of reduced humidity and increased dryness were less than the positive effects of the increased greenness and decreased heat on the ecology, and the ecological situation showed an improvement trend.

In order to further explore the changes of local ecological conditions in the study area, the normalized RSEI ecological index was divided into five grades according to the numerical interval of 0.2. The values from low to high represent ecologically poor, fair, moderate, good and excellent, respectively [19,20,23], and the area and proportion of each ecological level in each year was calculated (Table 3).

Table 3. Area and percentage change of each RSEI level in different years.

\begin{tabular}{|c|c|c|c|c|c|c|c|c|}
\hline \multirow{2}{*}{ RSEI Level } & \multicolumn{2}{|c|}{2007} & \multicolumn{2}{|c|}{2011} & \multicolumn{2}{|c|}{2014} & \multicolumn{2}{|c|}{2017} \\
\hline & $\begin{array}{c}\text { Area } \\
\left(\mathbf{k m}^{2}\right)\end{array}$ & $\begin{array}{l}\text { Pct. } \\
(\%)\end{array}$ & $\begin{array}{c}\text { Area } \\
\left(\mathbf{k m}^{2}\right)\end{array}$ & $\begin{array}{l}\text { Pct. } \\
(\%)\end{array}$ & $\begin{array}{c}\text { Area } \\
\left(\mathbf{k m}^{2}\right)\end{array}$ & $\begin{array}{l}\text { Pct. } \\
(\%)\end{array}$ & $\begin{array}{c}\text { Area } \\
\left(\mathbf{k m}^{2}\right)\end{array}$ & $\begin{array}{l}\text { Pct. } \\
\text { (\%) }\end{array}$ \\
\hline Level 1: Poor (0.0 0.2) & 6.24 & 2.5 & 9.41 & 3.7 & 24.99 & 9.1 & 11.63 & 4.2 \\
\hline Level 2: Fair (0.2 0.4) & 62.17 & 25.3 & 77.97 & 30.6 & 74.99 & 27.2 & 81.60 & 29.4 \\
\hline Level 3: Moderate (0.4 0.6) & 101.15 & 41.2 & 93.78 & 36.8 & 79.12 & 28.7 & 82.11 & 29.5 \\
\hline Level 4: Good (0.6 0.8) & 55.42 & 22.6 & 53.74 & 21.1 & 65.78 & 23.8 & 66.14 & 23.8 \\
\hline Level 5: Excellent (0.8 1.0) & 20.33 & 8.3 & 19.78 & 7.8 & 31.06 & 11.3 & 36.47 & 13.1 \\
\hline Total & 245.31 & 100 & 254.68 & 100 & 275.93 & 100 & 277.95 & 100 \\
\hline
\end{tabular}

Table 3 shows that, in 2007, the overall ecological quality of PZ was mainly at the moderate level (Level 3), with an area ratio of $41.2 \%$. The total areas of the ecologically good and excellent levels (Levels 4 and 5) were almost equivalent to the total areas of the ecologically poor and fair (Levels 1 and 2), which were $30.9 \%$ and $27.8 \%$, respectively. By 2011 , the proportion of the area with excellent, good and moderate levels decreased by $10.7 \%, 6.6 \%$ and $6.0 \%$, respectively, while the ecologically poor and fair levels increased by $48.0 \%$ and $20.9 \%$ respectively, indicating that the overall ecological condition of the PZ was degraded at the beginning of construction. By 2014, the ecological status of the PZ had 
undergone further changes, mainly with ecologically excellent and good areas beginning to increase slowly, increasing to $11.3 \%$ and $23.8 \%$, respectively, while the ecologically fair and medium areas decreased to $30.2 \%$ and $29.1 \%$, respectively, indicating that the ecological environment problems have been paid attention to during the construction process, and the ecological status has been improved a bit. However, it is worth noting that the proportion of ecologically poor areas greatly increased to $9.1 \%$ due to the impact of large-scale reclamation, which was at the time mainly in the form of bare soil and bare sand; hence, the study area still shows a decline trend of overall ecological quality. By 2017, with the further advancement of construction, the proportion of ecologically excellent areas continued to rise, with an increase of $25.0 \%$, ecologically poor areas decreased sharply, with a drop of $51.8 \%$, and ecologically fair, moderate and good areas increased slightly, rising to $29.4 \%, 29.5 \%$ and $23.8 \%$, respectively, indicating that the ecological status of the study area greatly improved. Thus, it can be seen that between 2007 and 2017, the ecological status of the study area was changing, with the overall ecology of the area showing a trend of first degradation and then improvement.

Figure 3 shows the changes in spatial distribution of the graded RSEI, with green, light green, yellow, orange and red representing the excellent, good, moderate, fair and poor ecological levels, respectively. In 2011, the ecologically fair and poor (orange-red) areas significantly increased with wider distributions, and the area with moderate ecology was significantly reduced mainly due to degradation of the environment in the central and northern regions compared with 2007, and there were also large areas in the southwest with fair and poor ecological levels due to land reclamation. By 2014, the ecology of the southeast, south and south-central areas improved compared with 2011, but there were many new areas in the north-central and southwest due to reclamation, most of which were in a state of poor ecology, which lowered the overall ecological level in 2014. By 2017, ecologically excellent area (green) in the north had further expanded, and the bare soil that appeared in the southwest and north-central areas due to reclamation was covered by vegetation; thus, the overall ecological situation improved.

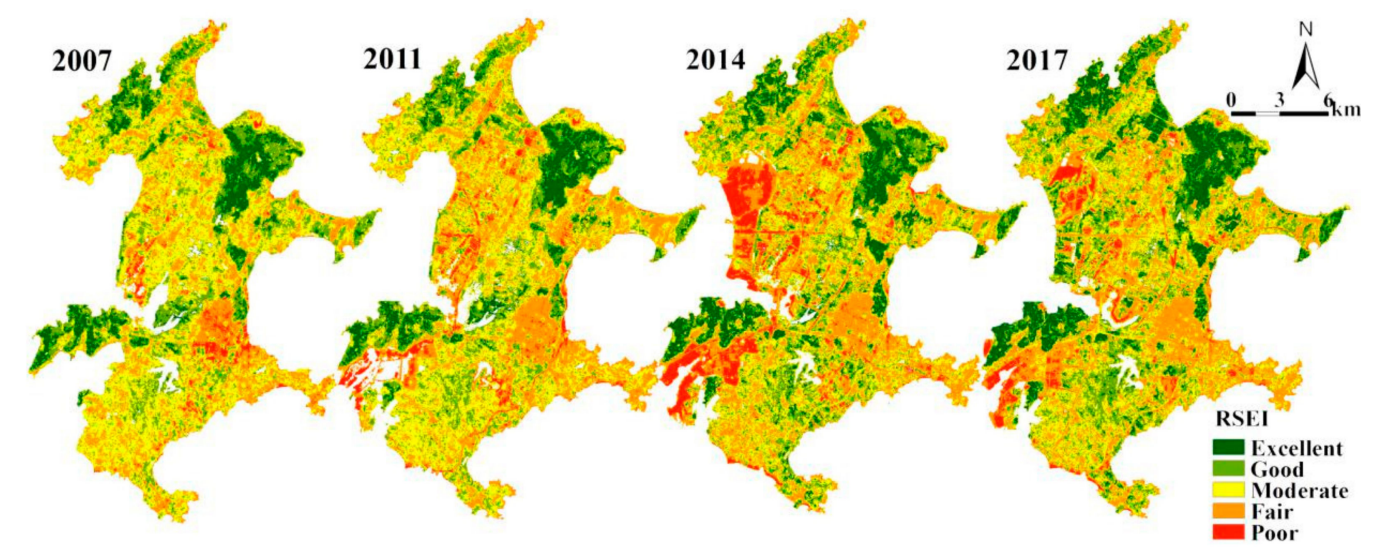

Figure 3. Five-leveled RSEI images of Pingtan Island in different years.

\subsection{Dynamic Changes in the Ecological Status of Pingtan Island}

In order to reveal the dynamic changes of the ecological status of the PZ and the impact of reclamation on the ecology in different time periods in detail, we divided the study area into two parts: The original area and the reclamation area. For the original area, the image difference method was used to obtain its ecological dynamic change information from 2007 to 2017 (Figure 4), and an area ratio of the corresponding changes was counted (Table 4). For the reclamation area, according to the image resolution and the actual land use situation of the study area, four land use types, namely water, vegetation, build-up land and unused land, were selected to reclassify the reclamation area by random forest classification, and then their ecological changes through land use changes were analyzed (Table 5). 




Figure 4. Change images of RSEI between 2007 and 2017.

Table 4. Percentage changes of ecological levels in Pingtan Island during 2007-2017.

\begin{tabular}{cccccc}
\hline $\begin{array}{c}\text { Ecological } \\
\text { Change Type }\end{array}$ & $\begin{array}{c}\text { Grade } \\
\text { Differential }\end{array}$ & \multicolumn{2}{c}{ 2007-2011 } & \multicolumn{2}{c}{ 2011-2017 } \\
\cline { 2 - 6 } & & $\begin{array}{c}\text { Area } \\
\text { Proportion (\%) }\end{array}$ & $\begin{array}{c}\text { Increase/Decrease } \\
\text { in Total (\%) }\end{array}$ & $\begin{array}{c}\text { Area } \\
\text { Proportion (\%) }\end{array}$ & $\begin{array}{c}\text { Increase/Decrease } \\
\text { in Total (\%) }\end{array}$ \\
\hline \multirow{3}{*}{ Improved } & +4 & 0.001 & & 0.009 & \\
& +3 & 0.067 & 15.077 & 0.319 & 32.190 \\
& +2 & 0.615 & & 27.868 & \\
\hline Unchanged & +1 & 14.394 & - & 54.355 & - \\
\hline \multirow{2}{*}{ Degraded } & 0 & 64.940 & & 10.879 & 13.455 \\
& -1 & 17.325 & & 2.060 & \\
\hline
\end{tabular}

Table 5. Percentage changes of land use type part 1 (a) and part 2 (b) in the land-reclamation area of Pingtan Island during 2007-2017.

\begin{tabular}{|c|c|c|c|c|c|c|c|c|}
\hline \multicolumn{9}{|c|}{ (a) } \\
\hline \multirow{2}{*}{ Land Use Type } & \multicolumn{2}{|l|}{2007} & \multicolumn{2}{|l|}{2011} & \multicolumn{2}{|l|}{2014} & \multicolumn{2}{|l|}{2017} \\
\hline & $\begin{array}{l}\text { Area } \\
\left(\mathbf{k m}^{2}\right)\end{array}$ & $\begin{array}{l}\text { Pct. } \\
(\%)\end{array}$ & $\begin{array}{l}\text { Area } \\
\left(\mathbf{k m}^{2}\right)\end{array}$ & $\begin{array}{l}\text { Pct. } \\
(\%)\end{array}$ & $\begin{array}{l}\text { Area } \\
\left(\mathbf{k m}^{2}\right)\end{array}$ & $\begin{array}{l}\text { Pct. } \\
(\%)\end{array}$ & $\begin{array}{l}\text { Area } \\
\left(\mathbf{k m}^{2}\right)\end{array}$ & $\begin{array}{l}\text { Pct. } \\
\text { (\%) }\end{array}$ \\
\hline Water & 8.95 & 89.48 & 2.30 & 22.63 & 0.61 & 6.01 & 0.23 & 2.26 \\
\hline Vegetation & 0.16 & 1.64 & 0.13 & 1.27 & 0.31 & 3.04 & 1.25 & 12.50 \\
\hline Build-up land & 0 & 0 & 0 & 0 & 2.62 & 25.95 & 4.08 & 40.67 \\
\hline Unused land & 1.05 & 10.52 & 7.73 & 76.10 & 6.57 & 65.00 & 4.47 & 44.57 \\
\hline Total & 10.17 & 100 & 10.16 & 100 & 10.12 & 100 & 10.03 & 100 \\
\hline \multicolumn{9}{|c|}{ (b) } \\
\hline \multirow{2}{*}{ Land Use Type } & 2007 & & 2011 & & 2014 & & 2017 & \\
\hline & $\begin{array}{l}\text { Area } \\
\left(\mathbf{k m}^{2}\right)\end{array}$ & $\begin{array}{l}\text { Pct. } \\
(\%)\end{array}$ & $\begin{array}{l}\text { Area } \\
\left(\mathbf{k m}^{2}\right)\end{array}$ & $\begin{array}{l}\text { Pct. } \\
(\%)\end{array}$ & $\begin{array}{l}\text { Area } \\
\left(\mathbf{k m}^{2}\right)\end{array}$ & $\begin{array}{l}\text { Pct. } \\
(\%)\end{array}$ & $\begin{array}{l}\text { Area } \\
\left(\mathbf{k m}^{2}\right)\end{array}$ & $\begin{array}{l}\text { Pct. } \\
\text { (\%) }\end{array}$ \\
\hline Water & 13.78 & 89.84 & 8.83 & 57.38 & 1.92 & 12.50 & 1.66 & 10.82 \\
\hline Vegetation & 1.12 & 7.11 & 0.33 & 2.12 & 2.38 & 15.45 & 7.88 & 51.19 \\
\hline Unused land & 0.48 & 3.05 & 6.23 & 40.50 & 11.09 & 72.04 & 5.85 & 37.99 \\
\hline Total & 15.39 & 100 & 15.39 & 100 & 15.39 & 100 & 15.39 & 100 \\
\hline
\end{tabular}


As seen in Table 4 and Figure 2, the ecological changes in the original area of PZ during 2007-2017 were relatively small, and were mostly based on ecological improvement level 1 and decline level 1. From 2007 to 2011, most of the original areas remained unchanged, which accounted for $64.940 \%$ of the total area, mainly distributed in the central, southern and northeastern corners. In addition, the degraded ecological area accounted for $19.983 \%$, of which the western and eastern areas were larger, while the ecological improvement area accounted for only $15.077 \%$, indicating that the degree of ecological degradation in the research area exceeded the degree of ecological improvement. From 2011 to 2017, the area with improved ecology accounted for $32.190 \%$, and the green tone that characterizes ecological improvement was mainly distributed in the northwest, the five major outlets (black dotted oval in Figure 4) and the periphery of the 36-foot lake (purple dotted oval in Figure 4). The area with declining ecology accounted for $13.455 \%$, and was mainly distributed in the surrounding areas of the central urban main road. This indicated that the overall ecological change was stable and rising.

Table 5 and Figure 4 show that the land use types in the reclamation area varied greatly during 2007-2017. In 2007, reclamation had not yet begun and was mostly in the form of water. By 2011, with the progress of reclamation projects, the water area was greatly reduced, and the vegetation was also reduced slightly. Meanwhile, the area of unused land increased rapidly, with an 11.9 times increase in the north-central region (Figure 5a) and a 6.3 times increase in the southwest region (Figure 5b). After that, the changes in the two regions were different. For the north-central region (Figure 5a), large-scale afforestation was carried out during the continuous blowing of sand so that the area of vegetation reached $51.19 \%$ by 2017. For the southwest corner (Figure 5b), in 2014, the water continued to decrease, and some unused land began to transform into construction land. In 2017, the reclamation was basically over, and the unused land was gradually covered by a large number of buildings and vegetation. Overall, the ecology of the reclamation area dropped sharply first and then rose slowly.

2007
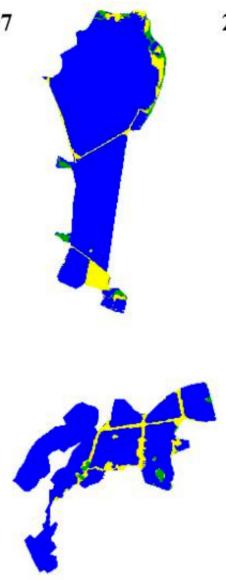

2011
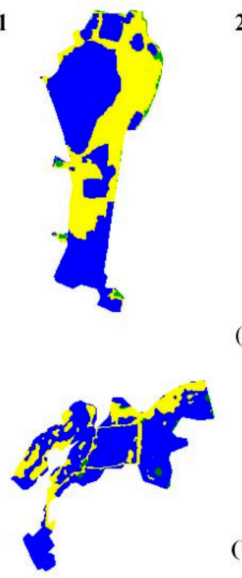

2014

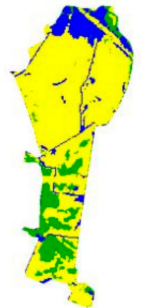

(a)

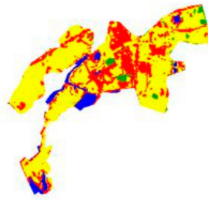

2017



Figure 5. Land use classification of part 1 (a) and part 2 (b) in reclamation areas.

\subsection{Ecological Effects of Overall Planning of Pingtan Island}

According to the master plan map of PZ [41] (Figure 5b), the development of the comprehensive experimental zone has been mainly concentrated in the central and western regions, excluding the southwest, north and northeast regions. The southwest corner and northeast corner of Pingtan Island are mostly mountainous areas with high vegetation coverage. Moreover, they have been less affected by human activities so far, so the ecological condition is good and remains basically unchanged. Besides, the main constructions in the north, south and east are afforestation on sand wasteland, forestland afforestation, green village construction and restoration of the basic forest belts. From the perspective of the spatial distribution of RSEI dynamic changes, these areas were the main distribution areas with the unchanged or improved ecological grade.

The ecologically degraded areas were mainly distributed in newly developed construction areas in the western, southwest and central new districts that had been greatly affected by human development 
activities (Figure 6a). They almost correspond to the locations of several development zones, shown in Figure $6 \mathrm{~b}$ (dotted oval), that were affected by ecological damage caused by human activities.

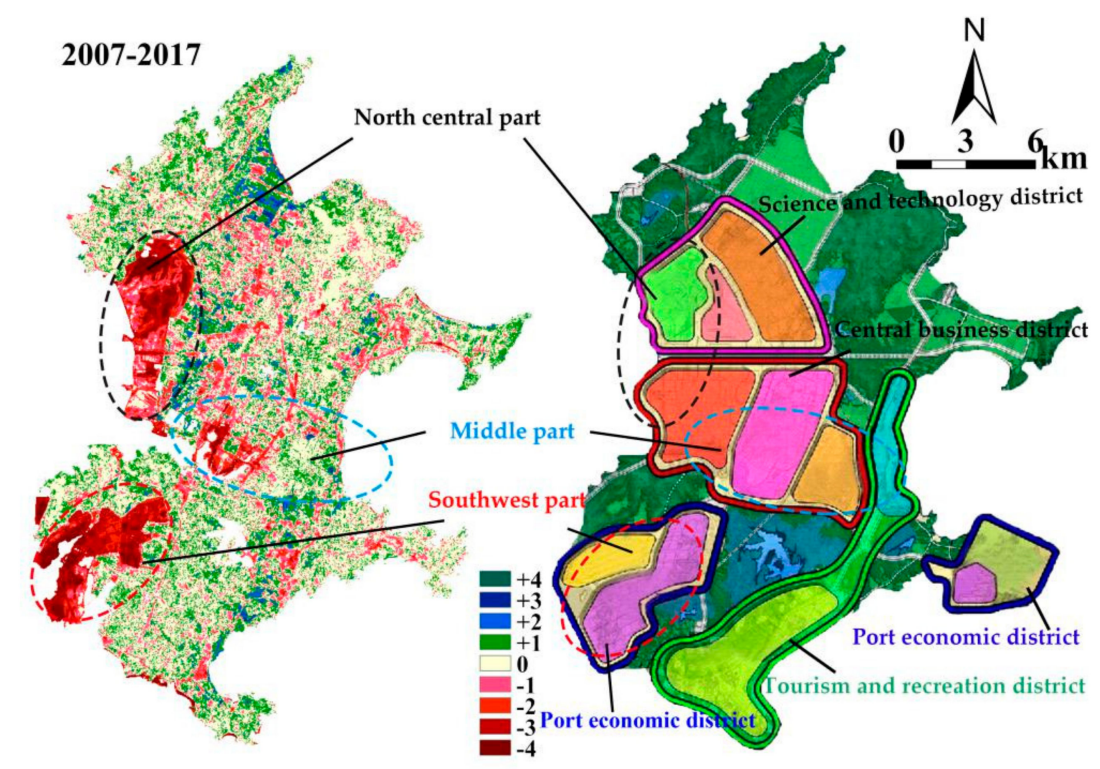

(a)

(b)

Figure 6. The contrast of the two images: (a) Change images of RSEI between 2007 and 2017; (b) master plan map of Pingtan Comprehensive Experimental Zone (PZ) (2010-2030).

Among them, the central area (blue dotted oval in Figure 6a) includes township areas such as Zhujing, Yucheng, Tancheng, etc. According to the overall planning of the experimental area and the construction target of the recent plan (2010-2015), the central part will be the main functional area of the future experimental area, and Zhuji, Yucheng and its adjacent areas have been designed as the first batch of development zones, which will be built into a multi-functional central business district. From 2007 to 2017, the area was changed from an agro-ecological landscape to an urban eco-landscape. Moreover, the land use type has changed greatly. For example, some major road networks have been newly formed, occuping a large amount of farmland and forest land; and large-scale areas of bare construction land have replaced the original green land, thus reducing the ecological status of the area.

The dramatic changes in the ecological conditions in the southwest and north-central parts were mainly due to the ecological impact of large-scale sand-blown land reclamation. According to the master plan map of PZ, the planned area within the entire experimental area is about $30 \mathrm{~km}^{2}$. The sea area in the southwest corner of the main island (the black dotted oval in Figure 6a) will make full use of the advantages of sea and air transportation to build a modern port economic and trade zone with important influence. Moreover, the north-central sea (red dotted oval in Figure 6a) is planned to be a scientific and technology district. In 2007, the two parts were still large areas of water. By 2014, there were large areas of bare land within the two areas (Figure 2), and the area of the reclamation had reached $30.62 \mathrm{~km}^{2}$. The land use type had been transformed from the good ecological status of seawater into building bare land, and the newly added bare land in a short period of time will inevitably have had a certain adverse impact on the local ecological environment. Therefore, it showed a deep red in the 2007-2017 ecological change map.

\section{Discussion}

The vulnerability of Pingtan Island's ecological environment is the result of the dual factors of natural conditions and human activities. Human development activities are the main reason for the 
recent ecological changes on the island. In the initial stage of construction, the overall ecological level of PZ declined mainly because the tract development of the experimental area brought about the destruction of the previous vegetation-based natural ecology, which made the originally fragile island ecology face greater pressure; in the middle and late stages of construction, the overall ecological level of PZ began to slowly recover, except for the reclamation area, mainly due to the promotion of ecological agriculture, urban greening and other measures and the construction of five major vents near the coastline, green corridors and green corridors around the island after the planning and construction of the experimental area. According to actual statistics, from 2011 to the end of 2016, more than $33 \mathrm{~km}^{2}$ of afforestation were completed in the experimental area, and the forest coverage increased from $29 \%$ to $35.82 \%$ [42]. Therefore, in the later construction of the experimental area, the contents of the PZ Environmental Master Plan (2011-2020) should be implemented, the coordinated development should be paid attention to and the green city should be built.

The reclamation area is a new land area in which the PZ uses sand-blown reclamation to protect farmland and save land resources. However, due to the greater intensity, the land use type has changed drastically, and the early stage is mostly in the form of bare soil and bare sand. The existence and destruction of the ecological environment of the land and offshore waters led to a downward trend in the overall ecology in 2014. By 2017, some areas had completed greening and construction. Among them, the total area of the newly built shelter forest of the north-central Xingfuyang group was over $16 \mathrm{~km}^{2}$ [43]. The ecological situation has been improved, and the overall ecological level has risen, but most of the ecological conditions are still in poor and fair grades. Among them, the main land use type of the Jinjingwan group in the southwest has been transformed from a water body to bare land. While nearly half of the north-central Xingfuyang group is covered by vegetation, half of the area is still bare soil, and most of the vegetation is still in a young state, contributing less to ecology. As the reclamation areas are all located in coastal areas, and Pingtan Island, one of the strong wind regions in the country, rages with wind and sand all year round, vegetation plays an important role in wind and sand fixation. Therefore, in the later construction, the scientific planning of the reclamation area should be carried out, the proportion of the planned area of construction land and green space should be coordinated and the ecological quality should be improved.

\section{Conclusions}

The remote sensing ecological index (RSEI) was used to analyze the ecological status and temporal and spatial trends and their causes. From 2007 to 2011, the ecological quality of PZ showed a slight decline mainly due to the large area development in the early stage of construction. From 2011 to 2014, the overall ecology of $\mathrm{PZ}$ was still in a declining state due to the large-scale reclamation project, but the ecology of the original area was improved. By 2017, the overall ecology had improved, which was attributed to the emphasis on ecological construction and protection during the construction of $\mathrm{PZ}$ and the active implementation of ecological measures. To sum up, the increase of bare soil in large areas of buildings will lead to regional ecological decline, but the implementation of scientific ecological planning is conducive to ecological recovery and construction. Therefore, in the construction process, in order to improve the overall quality, it is necessary to strengthen greening construction in the newly-built areas of the county, especially planting trees, which can not only prevent wind and sand, but also prevent soil erosion; for the old city, local renovation and reconstruction should be carried out; the original green areas with good ecology are supposed to continue to be repaired and protected to stabilize and enhance their ecological advantages; the reclaimed area needs a lot of afforestation.

Author Contributions: X.W. designed the research; Y.M. performed research and analyzed the date; Y.G. and X.H. collected and processed the data; X.W. and Y.M. wrote and revised the paper. The final manuscript is the result of the collaborative effort of all authors. All authors have read and agreed to the published version of the manuscript.

Funding: This research was funded by Nature Science Foundation of Fujian, China, grant number 2014J01156 and Key Technologies Program of Fujian Educational Committee, grant number JA15044. 
Acknowledgments: The authors sincerely thank the editors and anonymous reviewers for their kindly view and constructive suggestions.

Conflicts of Interest: The authors declare no conflict of interest.

\section{References}

1. Cao, W.; Li, R.; Chi, X.; Chen, N.; Zhang, H.; Zhang, F. Island urbanization and its ecological consequences: A case study in the Zhoushan Island, East China. Ecol. Indic. 2017, 76, 1-14. [CrossRef]

2. Kerr, J.T.; Ostrovsky, M. From space to species: Ecological applications for remote sensing. Trends Ecol. Evol. 2003, 18, 299-305. [CrossRef]

3. Katovai, E.; Burley, A.L.; Mayfield, M.M. Understory plant species and functional diversity in the degraded wet tropical forests of Kolombangara Island, Solomon Islands. Biol. Conserv. 2012, 145, 214-224. [CrossRef]

4. Yuan, C.; Shi, H.S.; Sun, J.K.; Zhen, G.; Ma, D.M. Evaluation on Island Resources and Environment Carrying Capacity under the Background of Urbanization. J. Nat. Resour. 2017, 32, 1374-1384.

5. Boyd, D.S.; Foody, G.M. An overview of recent remote sensing and GIS based research in ecological informatics. Ecol. Inf. 2011, 6, 25-36. [CrossRef]

6. Roerink, G.J.; Danes, M.H.G.I. Quantification of Ecological Changes by Remote Sensing. Geophys. Res. 2010, 12, 2010-4643.

7. Willis, K.S. Remote sensing change detection for ecological monitoring in United States protected areas. Biol. Conserv. 2015, 182, 233-242. [CrossRef]

8. Crétaux, J.-F.; Jelinski, W.; Calmant, S.; Kouraev, A.; Vuglinski, V.; Berge-Nguyen, M.; Gennero, M.-C.; Nino, F.; Abarca Del Rio, R.; Cazenave, A.; et al. SOLS: A lake database to monitor in the Near Real Time water level and storage variations from remote sensing data. Adv. Space Res. 2011, 47, 1497-1507. [CrossRef]

9. Ochoa-Gaona, S.; Kampichler, C.; Jong, B.H.J.D.; Hernández, S.; Geissen, V.; Huerta, E. A multi-criterion index for the evaluation of local tropical forest conditions in Mexico. Forest Ecol. Manag. 2010, 260, 618-627. [CrossRef]

10. Xu, H.Q. A new index-based built-up index (IBI) and its eco-environmental significance. Remote Sens. Technol. Appl. 2007, 22, 301-308.

11. Wen, X.L.; Xu, H.Q. Remote sensing analysis of impact of Fuzhou City expansion on water quality of lower Minjiang River, China. Sci. Geogr. Sin. 2010, 30, 624-629.

12. Suter, G.W.; Norton, S.B.; Cormier, S.M. A methodology for inferring the causes of observed impairments in aquatic ecosystems. Environ. Toxicolo. Chem. 2002, 21, 1101-1111. [CrossRef]

13. Mozumder, C.; Tripathi, N.K.; Tipdecho, T. Ecosystem evaluation (1989-2012) of Ramsar wetland Deepor Beel using satellite-derived indices. Environ. Monit. Assess 2014, 186, 7909-7927. [CrossRef] [PubMed]

14. Hazaymeh, K.; Hassan, Q.K. A remote sensing-based agricultural drought indicator and its implementation over a semi-arid region, Jordan. J. Arid Land. 2017, 3, 4-15. [CrossRef]

15. Yanchuang, Z.; Xinyuan, W.; Novillo, C.J.; Patricia, A.F.; René, V.J.; Fernando, T.M. Albedo estimated from remote sensing correlates with ecosystem multifunctionality in global drylands. J. Arid Environ. 2018, 157, 116-123.

16. Rodgers, K.S.; Kido, M.H.; Jokiel, P.L.; Eric, K.B. Use of Integrated Landscape Indicators to Evaluate the Health of Linked Watersheds and Coral Reef Environments in the Hawaiian Islands. Environ. Manag. 2012, 50, 21-30. [CrossRef] [PubMed]

17. Farhan, A.R.; Lim, S. Vulnerability assessment of ecological conditions in Seribu Islands, Indonesia. Ocean Coast. Manag. 2012, 65, 1-14. [CrossRef]

18. Mukherjee, N.; Siddique, G. Climate change and vulnerability assessment in Mousuni Island: South 24 Parganas District. Spat. Inf. Res. 2018, 26, 163-174. [CrossRef]

19. Xu, H.Q. A remote sensing index for assessment of regional ecological changes. China Environ. Sci. 2013, 33, 889-897. (In Chinese)

20. Hu, X.S.; Xu, H.Q. A new remote sensing index for assessing the spatial heterogeneity in urban ecological quality: A case from Fuzhou City, China. Ecol. Indic. 2018, 89, 11-21. [CrossRef]

21. Xu, H.Q.; Wang, M.Y.; Shi, T.T.; Guan, H.D.; Fang, G.Y.; Lin, Z.L. Prediction of ecological effects of potential population and impervious surface increases using a remote sensing based ecological index (RSEI). Ecol. Indic. 2018, 93, 730-740. [CrossRef] 
22. Bai, X.Y.; Du, P.J.; Guo, S.C.; Zhang, P.; Lin, C.; Tang, P.F.; Zhang, C. Monitoring Land Cover Change and Disturbance of the Mount Wutai World Cultural Landscape Heritage Protected Area, Based on Remote Sensing Time-Series Images from 1987 to 2018. Remote Sens. 2019, 11, 1332. [CrossRef]

23. Yue, H.; Liu, Y.; Li, Y.; Lu, Y. Eco-environmental quality assessment in China's 35 major cities based on remote sensing ecological index. IEEE Access 2019, 7, 51295-51311. [CrossRef]

24. Shan, W.; Jin, X.B.; Ren, J.; Wang, Y.C.; Xu, Z.G.; Fan, Y.T.; Gu, Z.M.; Hong, C.Q.; Lin, J.H.; Zhou, Y.K. Ecological environment quality assessment based on remote sensing data for land consolidation. J. Clean. Prod. 2019, 239, 118126. [CrossRef]

25. Chander, G.; Markham, B.L.; Helder, D.L.l. Summary of current radiometric calibration coefficients for Landsat MSS, TM, ETM+, and EO-1 ALI sensors. Remote Sens. Environ. 2009, 113, 893-903. [CrossRef]

26. Chavez, P.S., Jr. Image-based atmospheric corrections: Revisited and revised. Photogramm. Eng. Remote Sens. 1996, 62, 1025-1036.

27. $\mathrm{Xu}, \mathrm{H}$.Q. Image-based normalization technique used for Landsat TM/ETM+imagery. Geomatics Inf. Sci. Wuhan Univ. 2007, 32, 62-66. (In Chinese)

28. Rouse, J.W.; Haas, R.H.; Schell, J.A.; Deering, D.W. Monitoring vegetation systems in the Great Plains with ERTS. In ERTS Symposium Conference; NASASP-351: Greenbelt, MD, USA, 1973; pp. 309-317.

29. Eric, P.C. A TM Tasseled Cap equivalent transformation for reflectance factor data. Remote Sens. Environ. 1985, 17, 301-306.

30. Xu, H.Q. Analysis of Impervious Surface and its Impact on Urban Heat Environment using the Normalized Difference Impervious Surface Index (NDISI). Photogramm. Eng. Remote Sens. 2010, 76, 557-565. [CrossRef]

31. Jimenez-Munoz, J.C.; Cristobal, J.; Sobrino, J.A.; Sòria, G.; Ninyerola, M.; Pons, X. Revision of the Single-Channel Algorithm for Land Surface Temperature Retrieval from Landsat Thermal-Infrared Data. IEEE Trans. Geosci. Remote Sens. 2009, 47, 339-349. [CrossRef]

32. Boelman, N.T.; Stieglitz, M.; Rueth, H.M.; Sommerkon, M.; Grifin, K.L.; Shaver, G.R.; Gamon, J.A. Response of NDVI, Biomass, and Ecosystem Gas Exchange to Long-Term Warming and Fertilization in Wet Sedge Tundra. Oecologia 2003, 135, 414-421. [CrossRef] [PubMed]

33. Verbesselt, J.; Jonsson, P.; Lhermitte, S.; Aardt, J.V.; Coppin, P. Evaluating satellite and climate data-derived indices as fire risk indicators in savanna ecosystems. IEEE Trans. Geosci. Remote Sens. 2006, 44, 1622-1632. [CrossRef]

34. Jin, S.; Sader, S.A. Comparison of time series tasseled cap wetness and the normalized difference moisture index in detecting forest disturbances. Remote Sens. Environ. 2005, 94, 364-372. [CrossRef]

35. Baig, M.H.A.; Zhang, L.; Shuai, T.; Tong, Q.X. Derivation of a tasselled cap transformation based on Landsat 8 at-satellite reflectance. Remote Sens. Lett. 2014, 5, 423-431. [CrossRef]

36. Xu, H.Q. A new index for delineating built-up land features in satellite imagery. Int. J. Remote Sens. 2008, 29, 4269-4276. [CrossRef]

37. Essa, W.; Verbeiren, B.; Van der Kwast, J.; Van de Voorde, T.; Batelaan, O. Evaluation of the DisTrad thermal sharpening methodology for urban areas. Int. J. Appl. Earth Obs. Geoinf. 2012, 19, 163-172. [CrossRef]

38. Julia, B.; John, S.; Simon, H.; Raqueno, N.G.; Markham, B.L.; Radocinski, R.G. Landsat-8 Thermal Infrared Sensor (TIRS) Vicarious Radiometric Calibration. Remote Sens. 2014, 6, 11607-11626.

39. Nichol, J. Remote Sensing of Urban Heat Islands by Day and Night. Photogramm. Eng. Remote Sens. 2005, 71, 613-622. [CrossRef]

40. Sobrino, J.A.; Jimenez-Munoz, J.C.; Paolini, L. Land surface retrieval from LANDSAT TM5. Remote Sens. Environ. 2004, 90, 434-440. [CrossRef]

41. Fujian Urban and Rural Planning and Design Institute. Available online: http://www.fjplan.org/chgnr.asp? id=225 (accessed on 10 September 2019).

42. PTNET. Available online: http://en.ptnet.cn/index.html (accessed on 10 December 2019).

43. Sohu. Available online: http://www.sohu.com/a/167112662_263546 (accessed on 10 December 2019).

(C) 2019 by the authors. Licensee MDPI, Basel, Switzerland. This article is an open access article distributed under the terms and conditions of the Creative Commons Attribution (CC BY) license (http://creativecommons.org/licenses/by/4.0/). 